\title{
KANT AND THE PROBLEM OF AFFECTION
}

Claude Piché, Université de Montréal

This is a "postprint." The published version appeared in Symposium. Canadian Journal of Continental Philosophy, vol. 8, no. 2, 2004, p. 275-297.

On trouvera ici sur Papyrus la traduction FRANÇAISE intégrale et inédite de ce texte, dont la version anglaise publiée a été amputée de sa dernière section, sous le titre : "Kant et le problème de l'affection ».

\begin{abstract}
Starting with Vaihinger's famous trilemma which presents the different possibilities for explaining the origin of affection, I critically assess the classical theses of Jacobi, Aenesidemus-Schulze, Adickes, Kemp Smith, Paton and Allison on this subject. I argue that Kant is entitled to claim that both the empirical object and the thing in itself are the source of affection. It depends on the point of view one adopts: empirical or transcendental. But in this last case we face the famous problem: How could Kant dare to depict the thing in itself as the "cause" of affection? I claim that his description complies mutatis mutandis with the conditions imposed upon the principle of causality. If this principle states that the cause and the effect are "heterogeneous" and that the necessary cause may be a mere "indeterminate" something, then the affecting thing in itself, at its own level, satisfies both conditions: The thing in itself and sensation are radically heterogeneous and the essence of this thing remains for Kant totally "problematic", although its existence is declared certain. The Kantian use of the concept of causality is justified here by what must be called the self-referentiality of transcendental philosophy.
\end{abstract}

KEYWORDS : Kant, Jacobi, Aenesidemus-Schulze, Vaihinger's trilemma, thing in itself, causality

\section{1 - Vaihinger's trilemma}

Summing up a discussion that had been going on for over a century, Hans Vaihinger in the second volume of his famous Commentar (1892) came to the conclusion that there are three - equally unsatisfactory -- ways of explaining the source of affection in Kant's philosophy:

1-Either one means by the [affecting object] the thing in itself;...

2-Or we mean by the affecting object the objects in space;...

3-Or we admit a double affection: a transcendent one through the things in themselves, and an empirical one through the objects in space,...

\footnotetext{
${ }^{1}$ Hans Vaihinger, Commentar zu Kants "Kritik der reinen Vernunft", vol. 2 (Stuttgart/Berlin/Leipzig: Union deutsche Verlagsgesellschaft, 1892), 53.
} 
The last alternative is especially designed to obviate the difficulties inherent to the first two. But Erich Adickes, who was to become its main advocate, had to admit that the theory of double affection involves a serious problem, namely the fact that it does not find evidence in Kant's text itself. $^{2}$ We will therefore leave it aside and concentrate on the first two. However, part 1 and 2 of the trilemma also seem to lead to apparently insurmountable problems. In fact, Vaihinger claims that each of them contains an inner contradiction in that they blatantly go against Kant's own teachings.

Take the first case, the thing in itself is said to be at the origin of the affection of the knowing subject: Kant cannot help but describe this influence of the thing in itself over sensibility in terms of causality. Now, as Aenesidemus-Schulze quickly discovered, the category of "cause" (Ursache) can be legitimately used only in the field of experience, so that its application to the thing in itself is clearly in contradiction with the results of the Transcendental Analytic, and in particular with the principle of the Second Analogy of Experience. ${ }^{3}$

Similar difficulties arise in the second branch of the trilemma, which stipulates that it is appearance in space that engenders the affection. If, according to Kant's own definition, an appearance is no more than a mere representation in us, how could this same appearance affect sensibility from without and produce a representation in consciousness? Is it not Kant who taught that appearances are the product of affection? This reminds us of the famous objection raised by Jacobi. ${ }^{4}$

Instead of focusing our attention on the search for a third way in order to escape from the alleged contradictions, it might be useful to pay closer attention to the first two explanations, if only because both find textual evidence in Kant. In other words, rather than trying to correct the letter of Kant's Critique of Pure Reason by what one considers to be its spirit, why not see if it is possible to reconcile the spirit with the letter? Furthermore, why not try to harmonize these two solutions of the problem of affection, as they are expounded in the Critique. There is no reason to believe that the letter of the text should not be taken seriously, especially in cases in which, like the first explanation, Kant repeatedly uses the words "cause" (Ursache) and "ground"

${ }^{2}$ Erich Adickes, Kants Lehre von der doppelten Affektion unseres ich als Schlüssel zu seiner Erkenntnistheorie (Tübingen: J. C. B. Mohr, 1929).

${ }^{3}$ Gottlob Ernst Schulze, Aenesidemus oder über die Fundamente der von dem Professor Reinhold in Jena gelieferten Elementar-Philosophie (1792; reprint, Berlin: Reuther \& Reichard, 1911), 199.

${ }^{4}$ Friedrich Heinrich Jacobi, "Ueber den transzendentalen Idealismus", Appendix to David Hume über den Glauben, oder Idealismus und Realismus. Ein Gespräch, in Werke, ed. Friedrich Roth and Friedrich Köppen, vol. 2 (Darmstadt: Wissenschaftliche Buchgesellschaft, 1976), 291-310. 
(Grund) to describe the action of the thing in itself on human sensibility. ${ }^{5}$ Is it possible to conceive that by making a transcendental usage of the category of causality, he would willingly contradict his own critical philosophy in such an obvious fashion? Rather, there must be a sense in which Kant feels justified in his recourse to these terms. So there is no compelling reason to dismiss this terminology by attributing it to an "occasional looseness of formulation" on Kant's part, nor to the fact that Kant's "mode of expressing his doctrine of affection is misleading". ${ }^{6}$

Henry Allison, in his defense of Kant's transcendental idealism, attempts to solve the problems raised by the first branch of the trilemma in a manner which raises many questions.

Admittedly, there are many passages in which Kant refers mysteriously to a "transcendental ground" or "cause" of appearances. As I have argued elsewhere, however, this is not to be taken as an appeal to non-empirical explanation of what appears, but rather as a device for rejecting as vacuous any such explanation. ${ }^{7}$

In fact, Allison attempts to dispel the "mystery" surrounding the concept of a transcendental ground or cause by eliminating what he describes as any kind of "metaphysical" explanation in his Kant's Transcendental Idealism. In other words, he refuses to provide a solution to the problem of the thing in itself (as the cause of the affection of the knowing subject) by appealing to any form of knowledge. He stresses the Kantian distinction between knowing (Erkennen ) and thinking (Denken) in order to argue that the category of "cause" (acting here as a transcendental ground) is allowable only if understood in a strictly "logical" sense, suggesting a relation to a

\footnotetext{
${ }^{5}$ See for "Ursache", Kritik der reinen Vernunft (hereafter, the passages quoted in English will be taken from Norman Kemp Smith's translation of the Critique of Pure Reason), A 288/B 344, A 372, A 387, A 391, A 393, A 394, A 494/B 521; and for "Grund", ibid, A 49/B 66, A 277/B 333, A 380, A 393, A 538/B 566, A 613/B 641. For the purposes of this paper, we need not distinguish more precisely the thing in itself from the transcendental object. The passages quoted above refer indifferently to Ding an sich, Sache an sich, Gegenstand an sich, Objekt an sich, as well as to transzendentaler Gegenstand and transzendentales Objekt. I do not agree with Rescher's claim according to which Kant uses "cause" here in the sense of "ground" as this word is employed to designate the "merely intelligible and... regulative Principle of Sufficient Reason". I shall come back to this interpretation later. See Nicholas Rescher, "Noumenal Causality," in Kant's Theory of Knowledge, ed. Lewis White Beck (Dordrecht/Boston: Reidel, 1974), 176. In this Rescher was followed by John Visintainer, "Kant's Problem of Causality and the Ding-an-sich," Auslegung 21 (1997): 19-33.

${ }^{6}$ Rescher, "Noumenal Causality," 178. Gerd Buchdahl, "Realism and Realization in a Kantian Light," in Reading Kant. New Perspectives on Transcendental Arguments and Critical Philosophy, ed. Eva Schaper and Wilhelm Vossenkuhl (Oxford: Blackwell, 1989), 240, see also 244.

${ }^{7}$ Henry Allison, "Transcendental Idealism: The 'Two Aspect ' View", in New Essays on Kant, ed. Bernard den Ouden et al. (New York: Peter Lang, 1987), 168, emphasis mine. See also his Kant's Transcendental Idealism: An Interpretation and a Defense (New Haven \& London: Yale University Press, 1983), 250254.
} 
transcendental object that can only be "thought" of, but not known. For my part, I would like to argue that the reference to a mere concept, even to the "necessity" of that concept, is not sufficient to characterize Kant's argumentation here. ${ }^{8}$ In my view, Kant's critical discourse involves a specific form of knowledge and a legitimate claim to truth. In what follows, it will remain to be seen what restrictions a transcendental discourse, such as the one we find in the Critique of Pure Reason, is subject to when it refers to non-empirical elements of explanation. The question is: under what conditions can the thing in itself, taken as the cause of affection, be admitted as part of an explanation of the conditions of human knowledge? Thus, there must be elements within the first Critique able to shed light on the problematic of affection which lead to a coherent account of the respective role of things in themselves and appearances in this regard.

Instead of starting by classifying and discussing all the cases in the Critique where affection is explained in terms of appearances or in terms of things in themselves, it might be better to concentrate on a singular case, in which both forms of explanation seem to compete with one another. I shall start, therefore, with the study of the Anticipations of Perception in order to show that sensation can be construed in terms of an affection stemming from the object of perception, as well as from the thing in itself. This twofold explanation, that at first sight might appear confusing, if not plainly self-contradicting, is acceptable only if the transcendental level of discourse is carefully distinguished from the empirical. No doubt transcendental discourse involves some privileges, such as referring to the thing in itself as a transcendental object, still more important, however, is the fact that such a discourse is subject to certain restrictions that can only be assigned by critical reason itself, which are, in fact, present in Kant's transcendental philosophy. It will be our task to bring them to light. Otherwise, if the transcendental level of discourse was simply an invitation to transcend every limitation and reinstate dogmatic metaphysics, Strawson would be correct in claiming that the explanation of affection in terms of the thing in itself can only introduce "perversions" in a philosophy that first aimed at setting strict limits on human knowledge. It remains to be seen in what sense Kant does not contravene his own "principle of significance", according to which the bounds of sense coincide with the limits of experience. ${ }^{9}$

If, following this line of thought, a plausible answer can be found to the difficult question of transcendental causality (i.e. part one of Vaihinger's trilemma) or, in other words, if the transcendental use of the category of cause in this special case can prove legitimate, then it might open the possibility of providing an acceptable reading of the second branch of the trilemma,

\footnotetext{
${ }^{8}$ Henry Allison, "Transcendental Idealism: The 'Two Aspect' View", 173.

${ }^{9}$ P. F. Strawson, The Bounds of Sense. An Essay on Kant's "Critique of Pure Reason" (London: Methuen, 1966), 249, 254, 256.
} 
according to which appearance can also be seen to be the source of affection. What I propose can be considered as a reconstruction of the problematic of affection, drawing upon elements scattered throughout the Critique of Pure Reason. More specifically, I want to argue that the concept of cause used by Kant to designate the thing in itself belongs to a dynamical principle and that for this reason it has special privileges as becomes clear in the critical explanation of the Antinomies of pure reason. For instance, the concept of cause can refer to something that is totally different ("heterogeneous") from its effect so that sensation might as well be attributed -from a critical point of view -- to something that transcends the limits of experience.

\section{2 - realitas phaenomenon/realitas noumenon}

Although the problem of affection is introduced right at the beginning of the Transcendental Aesthetic, it is not in this section of the Critique that we learn about the question at hand: the question concerning the source of affection. In most cases, Kant does not determine what the cause of affection is with any precision. He attributes it to the object in general (Gegenstand, Objekt) or to the soul (Gemüth). In an exceptional passage the appearance resulting from the "affection" is related with the thing in itself (B 61). But as for the other occurrences of the word "affection", the reader has little choice but to guess what this affecting "object" might be.

One way of grasping this question is by considering a theme that is closely related to the problem of affection: sensation. On the first page of the Transcendental Aesthetic, sensation is described as the result of affection exerted upon the knowing subject. Sensation is defined as the empirical effect of the affecting object. "The effect of an object upon the faculty of representation, so far as we are affected by it, is sensation." (A 19-20/B 34, Kant's emphasis) Beyond the fact that this object is the cause of sensation, we do not learn anything more definite about it. If we turn to the section of the Critique of Pure Reason in which Kant deals extensively with the theme of sensation, we face a very different situation.

Let us first consider the formulation of the principle of the Anticipations of Perception. As we know, the central category of the principle is "reality" and the wording of this principle, in the first edition, gives an indication as to the nature of the reality in question.

In all appearances sensation, and the real which corresponds to it in the object (realitas phaenomenon) has an intensive magnitude, that is, a degree. (A 166, Kant's emphasis)

The reality that corresponds to sensation mentioned above is phenomenal, it belongs to the object of perception. As Kant writes a few pages later: "what corresponds in empirical intuition to 
sensation is reality (realitas phaenomenon)" (A 168/B 209). It is important to closely scrutinize these definitions, because in turning to the formulation of the problem of reality in the chapter on Schematism, we discover a wholly different picture.

Since time is merely the form of intuition, and so of object as appearances, that in the objects which corresponds to sensation is the transcendental matter of all objects as things in themselves (thinghood [Sachheit], reality). (A 143/B 182, emended trans.)

The question is posed in roughly the same terms as the formulation of the principle introduced above, but the answer is astonishing. No longer is it the phenomenal reality that "corresponds" to sensation, but rather the "transcendental matter" of the "things in themselves". This answer is quite puzzling, especially if we compare it with the line adopted in the Anticipations of Perception, in which reality is constantly referred to as empirical. One could be tempted to attribute it to a slip of the tongue on Kant's part, were it not for this passage of the Schematism being echoed in many others in the first Critique that deal with the thing in itself as the cause of appearances. Is there a way of making sense of these conflicting views concerning the source of affection? It looks as though one has to choose between realitas phaenomenon and realitas noumenon. The importance of this problem has not been lost on Kant's commentators.

Norman Kemp Smith finds the paragraph devoted to the category of reality in the chapter on Schematism "extremely difficult to decipher", and for this reason he prefers the developments of the Anticipations of Perception, which are "more precise and less ambiguous". ${ }^{10}$ This means that he is fully aware of the difficulties implicit in the reference to the thing in itself included in the description of the schema of reality. In any event, Kemp Smith was to settle the matter in his 1927 translation of the Critique of Pure Reason by making his an emendation of the text already proposed by Wille. Following the advice of Wille, he included a negation in the sentence quoted above, so that the passage on the schema of reality now reads: "...that in the objects which corresponds to sensation is not the transcendental matter of all objects as things in themselves..." (A 143/B 182, trans., 184) H. J. Paton, for his part, does not find the correction introduced by Wille "convincing". Like Kemp Smith, he attempts to consider the full scope of the difficulty presented by the definition of the chapter on Schematism. He is thus led to envisage the possibility that reality is seen from two different perspectives: "the matter of the phenomenal object" and the "matter of things in themselves". ${ }^{11}$ He is not ready, however, to sacrifice the

\footnotetext{
${ }^{10}$ Norman Kemp Smith, A Commentary to Kant's "Critique of Pure Reason" (New York: Humanities Press, 1950), 350-351.

${ }^{11}$ H. J. Paton, Kant's Metaphysic of Experience. A Commentary on the First Half of the Kritik der reinen Vernunft, vol. 2 (New York: Macmillan, 1936), 50-51, note 1. Nine years after the publication of the Critique, Kant, in his article against Eberhard, was to come back to the problem of sensation in terms very
} 
latter, as some are tempted to do, by interpreting the expression "things in themselves" in its "physical sense". For Paton, the fact that the "matter" in question is characterized by Kant as "transcendental" rules out such an interpretation. ${ }^{12}$

The reference to those two prominent Kant scholars shows clearly how subtle the explanation of sensation is and how strong, in the case of Kamp Smith, the tendency to eliminate the causality of the thing in itself is. We have seen that according to the introductory sections of the Transcendental Aesthetic, sensation is an "effect" that finds its source in an object that remains to be specified. But the principle of the Anticipations of Perception explicitly states that the object in question has a phenomenal reality. This suggests that it is the empirical object of perception that exerts "a degree of influence on the senses" (B 208). Although the treatment of the category of cause in fact belongs to the Second Analogy of Experience, in the Anticipations of Perception Kant already makes use of the principle of causality in order to explain the role of empirical reality in the genesis of sensation:

If this reality is viewed as cause [Ursache], either of sensation or of some other reality in the [field of] appearance, such as change, the degree of the reality as cause is then entitled a moment, for example the moment of gravity. ${ }^{13}$

But if the Anticipations establish that the empirical object must be seen as the "cause" of sensation, we should remember that this reading is not the only possibility for the Critique. Besides the schema of reality already alluded to, there are many passages in the fourth Paralogism (the first edition), where the thing in itself is declared as the "cause" of appearances. Even the text of the Second Analogy, while dealing with the empirical usage of the category of causality, unmistakably stipulates that the thing in itself is the source of affection. ${ }^{14}$ This does not solve our problem, but simply shows that both lines of reasoning are present in the Critique

similar to the ones used here: instead of the word "matter", he uses the word "stuff": "the objects as things in themselves give the stuff [Stoff] to the empirical intuitions..." Kant, Über eine Entdeckung nach der alle neue Kritik der reinen Vernunft durch eine ältere entbehrlich gemacht werden soll, AK VIII, 215.

${ }^{12}$ Béatrice Longuenesse suggests reading the expression "thing in itself" here in its weaker sense, that is, as the "empirical" thing in itself. According to her, this interpretation does not exclude the presence -- in the background -- of the thing in itself in its stronger meaning. See her Kant et le pouvoir de juger. Sensibilité et discursivité dans l'Analytique transcendantale de la Critique de la raison pure (Paris: Presses Universitaires de France, 1993), 344.

${ }^{13}$ Kritik der reinen Vernunft, A 168/B 210, emended trans., emphasis added; see the corresponding passage in the Second Analogy of Experience, A 208/B 254.

${ }^{14}$ Kritik der reinen Vernunft, A 190/B 235. For the other passages in which the thing in itself is declared to be at the origin of appearances, see note 6 above. 
of Pure Reason and that Kant seems ready to live with them both. In fact, he sustains both of them simultaneously. If we do not wish to adopt Vaihinger's somewhat rash judgment, that maintaining the two already self-contradicting theories of affection inevitably leads to further contradictions, we must be ready to investigate the conditions under which both explanations can appear equally acceptable to Kant.

\section{3 - Empirical and Transcendental Discourses}

The affection that manifests itself in sensation can be attributed, as we have just seen, to appearance as well as to the thing in itself. But from the standpoint of experience there is, truthfully, no need to distinguish between appearances and things in themselves. We might well distinguish between the raindrops, as the "physical" thing in itself, and the rainbow, as their appearance (A 45/B 62-62), but this distinction would remain on an empirical level and it is not relevant to the problematic of affection in the Critique of Pure Reason. The differentiation of the two affecting objects pertains to transcendental philosophy as such.

The transcendental concept of appearances in space... is a critical reminder that nothing intuited in space is a thing in itself, that space is not a form inhering in things in themselves as their intrinsic property, that objects in themselves are quite unknown to us, and that what we call outer objects are nothing but mere representations of our sensibility the form of which is space. The true correlate of sensibility, the thing in itself, is not known, and cannot be known, through these representations; and in experience no question is ever asked in regard to it. (A 30/B 45)

From the point of view of experience, it is no use to know that every object we encounter is an appearance. On the contrary, from this empirical perspective, we are convinced that the things with which we deal in our everyday life are the real things, the things in themselves.

In all problems which may arise in the field of experience we treat these appearances as objects in themselves, without troubling ourselves about the primary ground of their possibility (as appearances). ${ }^{15}$

The question concerning the ground of the possibility of appearances is clearly not an empirical one, it pertains exclusively to transcendental philosophy. If the concept of appearance in its transcendental sense is introduced as a "critical reminder", this simply suggests that the question concerning the ground of these appearances is specific to the enterprise of Kant's Critique of

${ }^{15}$ Kritik der reinen Vernunft, A 393. See also Kant, Preisschrift über die Fortschritte der Metaphysik, AK. XX, 269. 


\section{Pure Reason.}

But now, the point that must be clarified concerns the meaning of the word "transcendental" itself. It is well known that Kant sometimes uses the word as a synonym of "transcendent", however, when he actually defines it, he refers to the special status of the investigation taking place in the Critique. Critical investigation differs from all other kinds of knowledge in that it is not oriented directly towards the object. Transcendental philosophy is not concerned with the immediate knowledge of an object, and in this way it diverges from all other science, even metaphysics, which seeks to outline the very essence of its objects without any further precaution. Kant tends to view metaphysics as "dogmatic", in that the word itself describes the process of an investigation that has not previously submitted its cognitive tools to a critique. Critical investigation is anti-dogmatic per defenitionem because it does not start by taking for granted the accessibility of its object.

I entitle transcendental all knowledge which is occupied not so much with objects as with the mode of our knowledge of objects in so far as this mode of knowledge is to be possible a priori. ${ }^{16}$

This definition of "transcendental" taken from the second edition of the Critique of Pure Reason is explicit: the word delineates the status of an investigation focused on the "mode of our knowledge", rather than the object to be known. In short, a transcendental discourse concerns the "knowledge... of our knowledge". Hence, it initiates a special kind of reflection about knowledge. This reflection is specific in that the knowledge under scrutiny is our a priori knowledge. More precisely, transcendental investigation is geared toward answering our question about "synthetic" a priori knowledge (B 40). In this sense, "transcendental" is emblematic of the main question in Kant's theoretical philosophy: "How are a priori synthetic propositions possible?"

This question is another way of acknowledging the challenge posed by Hume's scepticism concerning the universality and necessity of the law of causality. According to Kant, Hume raised a transcendental question, but did not have the conceptual means to answer it. Transcendental discourse, it follows, is an attempt to provide an answer to Hume's question. Compared with the discourse of experience, this discourse is situated on a higher level. As Maclachlan suggests, these two levels can be compared, in Tarskian terms, with the relation between a meta-language and its object-language. ${ }^{17}$ There are issues that can be dealt with in a

\footnotetext{
${ }^{16}$ Kritik der reinen Vernunft, B 25, Kant's emphasis; see also Prolegomena, AK IV, 293, 374.

${ }^{17}$ D. L. C. Maclachlan, "The Things in Themselves Appear in a Meta-Language," in the Proceedings of the Eighth International Kant Congress, ed. Hoke Robinson, vol. 2, part 1 (Milwaukee: Marquette
} 
meta-language that could not possibly be formulated from the standpoint of an object-language. In this sense, transcendental critique is a meta-knowledge, designed especially to explain the possibility of first level knowledge: experience. This is precisely the manner in which the distinction between appearance and thing in itself operates. But such a critique, we must keep in mind, also represents a form of knowledge. This fact is taken for granted in the definition quoted above: "I entitle transcendental all knowledge..." The Prolegomena introduce transcendental philosophy as a "new science", as a science that offers, like every other science, a claim to "truth". ${ }^{18}$ In this case, the certainty claimed is not a merely relative or hypothetical one, it is "apodeictic (philosophical) certainty" (A XV).

The outcome of such an investigation is that knowledge involves formal as well as material conditions. As we know, the formal conditions are all a priori, they are imposed by the knowing subject upon the object; whereas the material conditions are always a posteriori. When confronted with the material conditions, the subject recognizes that, contrary to what happens with the formal conditions (viz. space, time, and the categories), it does not itself generate the manifold of the object of experience. This manifold must be given empirically through sensation. But since sensation can only take place within the framework of space and time, in other words, since the form as well as the matter of sensation can only be representations in the subject, this very sensation must be related to something real outside the scope of appearances: the thing in itself. That is, the conclusion arrived at here is strictly the product of a selfexamination of the faculty of knowledge and of the elementary components of the object of experience. It is only because the knowing subject measures through the critical process the limits of its active intervention in the genesis of experience, that it cannot help but admit that the spatio-temporal framework imposed upon the object of perception entails, as a counterpart, the existence of an unknown something beyond the phenomenal world. ${ }^{19}$ In order to explain the

University Press, 1995), 156.

${ }^{18}$ Prolegomena, AK IV, 279, 317.

${ }^{19}$ See Kant, Grundlegung zur Metaphysik der Sitten, AK IV, 451. In his book Der philosophische Kritizismus, Alois Riehl has rightly noticed that the affirmation of the reality of the thing in itself stems from a critical argument: "The result of our account of the methodological concepts of appearance and of its correlate, the thing in itself, is that Kant taught without the slightest hesitation the existence of the things, not simply because he found no reason to sublate it [i.e. the thing in itself, C.P.], but because at the outset of the investigation of a priori knowledge and of its constitution the existence of the things came out to be grounded." Alois Riehl, Der philosophische Kritizismus. Geschichte und System, vol. 1, Geschichte des philosophischen Kritizismus, 3rd ed. (Leipzig: Kröner, 1924), 563. This is an important point to make, without it one could be tempted, like Adickes, to attribute Kant's assumptions concerning the thing in itself not to a transcendental motive, but to a psychological one. Adickes sees Kant's realism as an existential component of his personality, and not as a philosophical necessity related to the critical investigation. He very often refers to Kant's "stark realistisch gefärbten Art seines Erlebens", which is 
necessity of sensation as the material condition of the appearances in the subject's consciousness, Kant is compelled to assert the actuality of a transcendent cause of these material conditions, and for this he has at his disposal only the tools that are provided a priori by the understanding: the category of cause (and of existence). Because he applies it to the thing in itself as a transcendent entity, he clearly makes "transcendental use" of it, bringing us back to the heart of the difficulty encountered in the first branch of Vaihinger's trilemma. ${ }^{20}$

\section{4 - The Various Kinds of Transcendental Use of the Categories}

Kant stresses constantly in the first Critique the fact that no transcendental employment of the categories can be allowed. These categories, so the Analytic teaches us, are only valid within the realm of experience. We must ask the question: why would Kant allow himself to

strictly in accordance with his scepticism of Kant's capacity to provide "scientifically (i.e. transcendentalphilosophical) grounded assertions" about the existence or the non-existence of the thing in itself. See Erich Adickes, Kants Lehre von der doppelten Affektion unseres ich, 2, 36, 45; see also his book, Kant und das Ding an sich (Berlin: Pan Verlag Rolf Heise, 1924), 16, 60, 93. George Schrader also lays stress on Kant's realism as a "private view": "The Thing in Itself in Kant's Philosophy", in Kant. A Collection of Critical Essays, ed. Robert Paul Wolff (New York: Doubleday, 1967), 174, 177. For my part, I would like to take the opposite stand, and argue that the affirmation of the existence of the thing in itself is necessarily implied by the account Kant intends to give of the possibility of experience as a whole.

${ }^{20}$ In order to circumvent the problem posed by this transcendental use of the categories of causality and of existence, a very tempting alternative consists in interpreting the relation between appearance and thing in itself with the help of the chapter devoted to the distinction between Phenomena and Noumena.

Because we must think the thing in itself as being the correlate of the appearances, why not conceive the thing in itself as a pure object of thought, as an ens rationis, as a Verstandeswesen, in a word, as a Noumenon. Moltke S. Gram, however, has convincingly shown that there is a strict difference between the thing in itself and the Noumenon. In fact, the thing in itself can appear in sensibility, it is the correlate of the appearance, whereas the Noumenon "does not affect our modes of intuition". See his The Transcendental Turn: The Foundation of Kant's Idealism (Gainesville: University of Florida Press, 1984), 46. This only emphasizes the important difference between the problematic of the thing in itself raised in Transcendental Aesthetic, and the problematic of the chapter on Phenomenon and Noumenon. In the first case, the thing in itself plays the role of an indispensable correlate of the appearance, in the second case, the Noumenon is introduced as a limiting concept designed "to curb the pretensions of sensibility", that is, of empiricism (See Critique of Pure Reason, A 255/B 311). Admittedly, both problematics, at times, overlap in the chapter on Phenomena and Noumena, but that is not a sufficient reason to interpret the correlate of appearances as "thought-things" (Nicholas Rescher, "On the Status of 'Things in Themselves' in Kant", Synthese 47 (1981): 299), as a mere "postulate" (Rescher, "Noumenal Causality," 181), or as a "limiting concept" (Schrader, "The Thing in Itself in Kantian Philosophy," 181, note 1). It is hard to believe that Kant would have considered the thing in itself as something we might only "think" of (Hoke Robinson, "Two Perspectives on Kant's Appearances and Things in Themselves," Journal of the History of Philosophy 32 (1994): 431, 435, 441), so that he would have attributed to it only a "thought existence" (Horst Seidl, "Bemerkungen zu Ding an sich und transzendentalem Gegenstand in Kants Kritik der reinen Vernunft," Kant-Studien 63 (1972): 307). 
make a transcendental use of causality in contemplating the thing in itself as the correlate of appearances? This employment is no doubt transcendental since the category is applied to a thing that lies outside the realm of experience, outside of space and time. Why would Kant tolerate such an exception? First of all, it must be acknowledged that this transcendental employment enjoys a unique status, thus it cannot be identified with the main kinds of transcendental use the Critique condemns. The first of these proscribed uses is to be found in the appendix to the Analytic: the Amphiboly of the Concepts of Reflection. Within, Kant criticizes philosophy that does not take seriously the ontological difference between sensible and intellectual representations. In the absence of this previous examination of the nature of our representations, Leibniz proposed an "intellectual system of the world" in which he "intellectualised appearances". Leibniz used the concepts of the understanding "transcendentally" because the specificity of the objects accessible to our knowledge was not taken into account (A 270-1/B 326-7, A 289/B 345). The same cannot be said of the use of the category of cause in question, because Kant's employment is made precisely from a critical point of view, in order to explain the very nature of the objects available to us through sensibility. This use is thus not based on an amphiboly; on the contrary, it is especially aimed at elucidating the confusion.

The same goes for the transcendental use of the categories that is made in the Transcendental Dialectic. ${ }^{21}$ This use does not depend on a mere error of judgment, it is instead forced by reason's own principles, which are from the start declared "transcendent". As a distinct faculty, reason turns toward the "absolute", that is, the "unconditioned" that closes all chains of conditions in experience (A 326/B 382, A 307-8/B 364). With the help of a series of truncated syllogisms, the three ideas of pure reason enjoin the subject to gain knowledge of the unconditioned itself. For example, in the third Antinomy, dogmatic metaphysics attempts to pass judgment on a free cause and in the fourth on the bearer of the ultimate condition of all things in the world: an absolutely necessary being. Kant's critical solution in these cases consists in stating that through our categories, we cannot know anything about the unconditioned, that we cannot even understand how a spontaneous cause would act, no more than we can attach any meaning to the modal concept of "absolute necessity". The three transcendental ideas of reason represent the ambitions of dogmatic metaphysics, and Kant shows that no knowledge can be expected from this field. The rational principles involved do not provide any objective knowledge, they serve merely as regulative principles.

All things considered, the way in which the problem of the thing in itself as the correlate

\footnotetext{
${ }^{21}$ In this context, Kant speaks more specifically of a "transcendent use" of the understanding. See Prolegomena §45, AK. IV, 333.
} 
of the appearances is formulated bears no resemblance to the transcendental use of the categories made in the ideas of pure reason. Kant does not claim that the correlate of the appearances is unconditioned nor do we know if it is conditioned or not; we do not need to know: "when I view all things not as phenomena but as things in themselves, and as objects of the mere understanding, then despite their being substances they can be regarded, in respect to their existence, as depending upon a foreign cause. ${ }^{122}$ Dogmatic metaphysicians wanted to establish a science of transcendent objects (the soul, the world, God), while transcendental philosophy, in explaining the scope of possible knowledge, just has to point to an unknown cause of appearances. The critical philosopher does not have to know more in order to explain the possibility of experience. In this sense, the thing in itself does not claim a status different from that of transcendental apperception -- the ultimate condition of the application of every category. Even though the transcendental unity of apperception is considered "the highest point" (B 134) of transcendental philosophy, it is by no means declared "absolute". This would involve reason in a dialectic statement, which is precisely the case of the first Paralogism. In the transcendental Deduction, the transcendental subject can perform its functions while remaining in itself perfectly unknown, "a mere something in general" (A 355). The criterion for every discourse on the transcendental subject and the transcendental object is the "possibility of experience". The transcendental subject and object are referred to only in their relation to it. They represent the ultimate conditions of the possibility of experience: the former being the ultimate condition of the formal conditions and the latter the ultimate background of the material conditions of experience. It is only in this sense that the interrogation of the thing in itself is rendered necessary. If we read the end of an argument partly quoted above, the philosophical character of this necessity appears clearly.

In all problems which may arise in the field of experience we treat these appearances as objects in themselves, without troubling ourselves about the primary ground of their possibility (as appearances). But to advance beyond these limits the concept of a transcendental object would be indispensably required. (A 393)

To be sure, the main problem posed by the first branch of Vaihinger's trilemma has not

\footnotetext{
${ }^{22}$ Kritik der reinen Vernunft, A 206/B 251-252, emphasis added. Therefore, I cannot agree with Nicholas Rescher when he associates the problem of the thing in itself, as the correlate of the appearances, with the search for the unconditioned: "But correlative with the conception of the conditioned object of perception goes that of an unconditioned noumenon. This conception is warranted and justified because it answers to the inexorable demands of a Principle of Sufficient Reason ('the unconditioned, which reason, by necessity and by right, demands... [something] to complete the series of conditions.')" "Noumenal Causality," 176.
} 
yet been solved. Even though we have seen that it is not required to prove that the status of the thing in itself is unconditioned (as in the ideas of the Dialectic), there is nevertheless a transcendental use of the category of cause that is made here, thus the question remains open as to whether or not Kant thereby contradicts the explicit lessons of the Analytic concerning the legitimate sphere of application of the categories.

Within the developments of transcendental philosophy, which aim primarily at circumscribing the domain of legitimate knowledge, it must be possible to extrapolate, if not discover, some of the guidelines for this higher level discourse. This pertains not to critical philosophy as such, but to what Lewis White Beck calls a "meta-critique of pure reason". I would like to retain the programmatic remarks made by Beck in order to see if they can be of some help in solving the problem we are now facing.

[Kant] has no explicit theory of how we come to know of the operations and faculties or abilities of the mind. A detailed articulation of his informal procedure, however, would constitute a meta-critique of pure reason, but an internal one, continuous with the critical philosophy itself. I believe it would take the form I have sketchily outlined and would not be in conflict with any of the positive teachings of the Critique of Pure Reason. Most particularly it would not require us to have knowledge which the Critique teaches we cannot have. $^{23}$

After having noticed that Kant had not paid sufficient attention to the methodological problems of transcendental philosophy, Beck goes on to claim not only that there must be no conflict between this methodology and the "positive teachings" of the Critique, but also that there must be a continuity between the transcendental principles and the discourse that formulates them. These remarks are compatible with a line of thought that I have already begun to develop elsewhere, and that can be labelled, following Rüdiger Bubner, the "self-referentiality" of Kant's transcendental philosophy. ${ }^{24}$ This form of self-reflexivity simply means that transcendental investigation, as a higher level discourse, cannot be ruled by its object-discourse -- viz. experience as a field where it would find empirical confirmation -- but in some way by itself. In

\footnotetext{
${ }^{23}$ Lewis White Beck, "Towards a Meta-Critique of Pure Reason," in the Proceedings of the Ottawa Congress on Kant in the Anglo-American and Continental Traditions, ed. Pierre Laberge, François Duchesneau \& Bryan Morrisey (Ottawa: University of Ottawa Press, 1976), 192-193, Beck's emphasis.

${ }^{24}$ See my "Self-Referentiality in Kant's Transcendental Philosophy," in the Proceedings of the Eighth International Kant Congress, vol. 2, part 1, 259-267; and Rüdiger Bubner, "Was heisst Synthesis?," Antike Themen und ihre moderne Verwandlung (Frankfurt: Suhrkamp, 1992), 110. [ Note of 2019: see also my contribution "Kant on the 'Conditions of the Possibility' of Experience", in: S. Hoeltzel and H. Kim (eds), Transcendental Inquiry. Its History, Methods and Critiques, Cham (Zwitzerland), Palgrave Macmillan, 2016, p. 1-19. The 'preprint' version of this article can be found here on Papyrus. ]
} 
other words, it must be governed by the very transcendental principles that it discovers in the course of the critical investigation: there are no other guidelines available. In the present case, it might be useful to ask if the principle of causality is also binding -- in some sense that remains to be clarified -- for the exposition of the problem of the thing in itself and, if this is the case, how it fulfils this task.

\section{5 - The special case of the dynamical categories}

It must be noted that the category of causality (as well as the category of existence, that I will leave aside here), which Aenesidemus-Schulze accuses Kant of employing illegitimately, is of a specific kind. It belongs to what Kant calls the dynamical, as opposed to the mathematical, categories. He establishes this distinction repeatedly in the Analytic because it marks an important division in the table of the transcendental principles. As we know, the first two principles are considered "mathematical", while the Analogies of Experience and the Postulates of Empirical Thought in general are dynamical principles. These latter do not deal with the possible measurement of the appearances but rather with their existence, which cannot be known in anticipation. The object must first be given empirically in order to be acknowledged as real, thus the dynamical principles regulate a priori the existence of appearances that must first be given through perception, that is, a posteriori.

It stands quite otherwise with those principles [i.e. dynamical, C.P.] which seek to bring the existence of appearances under rules a priori. For since existence cannot be constructed, the principles can apply only to the relations of existence... If , however, a perception is given in a time-relation to some other perception, then even although this latter is indeterminate, and we consequently cannot decide a priori what it is, or what its magnitude may be, we may none the less assert that in its existence it is necessarily connected with the former in this mode of time. ${ }^{25}$

Attention must be drawn to the fact that the correlate of the "given" perception is "indeterminate". This is an important feature of the dynamical categories of relation and will prove relevant to the problem of the affecting object. Kant stresses that it is impossible to determine a priori "what" this correlate might be. This becomes especially obvious in the exposition of the principle of causality, in which the givenness of the effect entails that it stands "in relation to some preceding point in time" and that it refers to "something else in general

\footnotetext{
${ }^{25}$ Kritik der reinen Vernunft, A 179/B 221-2, Kant's emphasis. The second occurrence of the expression a priori has been omitted in the translation of Kemp Smith, 210-211.
} 
[etwas anderes überhaupt]". ${ }^{26}$

A second point worthy of note in the characterisation of the dynamical categories is the "heterogeneity" of the terms involved. As compared to the mathematical principles, in which the pure and homogeneous intuition of space and time is the object of the synthesis, the connection between the correlates of the principle of causality is a synthesis of "heterogeneous" elements (B 201). This feature concerning the status of cause and effect has been amply stressed by Hume, ${ }^{27}$ and it deserves no particular attention as long as the principle of causality is employed within the field of experience, where heterogeneity is understood, to paraphrase the Prolegomena, like the difference in nature between the sun, that emits rays of light, and the stone, on which a certain degree of warmth is felt.

However, these two features become engaging as soon as we leave the Analytic and enter the Transcendental Dialectic. The inability for the dynamical categories to construct $a$ priori the existence of their object proves, indeed, to be an advantage. Since the categories of relation are not restricted to homogeneous parts (as is the case for the mathematical categories), their transcendental use in the third and fourth Antinomy allows for a positive solution to these dialectical conflicts of reason while the mathematical Antinomies end up being plainly contradictory. ${ }^{28}$ Hence in the mathematical connection of the series of appearances no other than a sensible condition is admissible, that is to say, in the dynamical series of sensible conditions, a heterogeneous condition, not itself a part of the series, but purely intelligible, and as such outside the series, can be allowed. In this way reason obtains satisfaction and the unconditioned is set prior to the appearances, while the invariably conditioned character of the appearances is not obscured, nor their series cut short, in violation of the principles prescribed by the understanding." My point is the following: if one wants to learn more about the transcendental use of the category of causality with respect to the thing in itself, one would be well advised to consult the transcendental use of this category specific to the third Antinomy, in which the problem of intelligible causality is extensively treated. In other words, I propose to draw a

\footnotetext{
${ }^{26}$ Kritik der reinen Vernunft, A 194/B 239, Kant's emphasis. See ibid., A 368: "Now the inference from a given effect to a determinate cause is always uncertain, since the effect may be due to more than one cause."(emphasis mine) See also Kritik der Urteilskraft, §88, AK. V, 457.

${ }^{27}$ David Hume, An Enquiry Concerning Human Understanding, Sect. IV, Part I, in Enquiries, ed. L. A. Selby-Bigge (Oxford: The Clarendon Press, 1902), 29.

${ }^{28}$ Kritik der reinen Vernunft, A 530-531/B 558-559: "But the concept of the understanding, which underlies these ideas, may contain either a synthesis solely of the homogeneous (which is presupposed alike in the composition and the division of every magnitude), or a synthesis of the heterogeneous. For the heterogeneous can be admitted as at least possible in the case of dynamical synthesis, alike in causal connection and in the connection of the necessary with the contingent.
} 
parallel between the problem of the thing in itself as it arises in the Aesthetic and the question of transcendental freedom as a form of causality in the Dialectic. One must, of course, remain conscious of the danger, to which I have already warned, of understanding this bringing together of the two questions as more than a parallel. These two transcendental usages of causality are in fact different, but the critical exposition and solution of the third Antinomy furnishes indispensable conceptual tools with which the causality of the thing in itself can be understood from a transcendental vantage point. We just have to keep in mind that the latter problem is not identical to the question raised in the third Antinomy, which pertains to freedom as the "sensibly unconditioned condition of appearances" (A 557/B 585, italics added). As we have already seen, the thing in itself as the cause of appearances is not related to its being conditioned, nor unconditioned. This aspect remains totally indeterminate.

The critical solution of the third Antinomy is interesting in that it admits two lines of explanation for "one and the same effect [eben derselben Wirkung]" (A 536/B 564). This is reminiscent of the two -- apparently competing -- explanations of sensation expounded in the schema of reality and in the Anticipations of Perception. The problem with a spontaneous cause, as it is described in the third Antinomy, lies in the fact that from the perspective of transcendental realism, there is no way of reconciling the free cause with the determinism ruling the empirical experience. In fact, transcendental realism is the standpoint of common sense, insofar as the empirical object is regarded as the real thing -- the thing in itself -- together with its spatial and temporal features. Only transcendental idealism, Kant argues, provides a solution to the problematic of freedom, in that it enjoins us to consider the empirical object not as a thing in itself, but as an appearance. The perspective adopted in order to produce this solution is none other than that of the transcendental philosopher, that is, the point of view from which one is compelled to admit that there must be something beyond the mere appearances which serves as their grounds. If we leave aside the fact that the following passage seeks to solve the question of the possibility of a "spontaneous" cause, the way in which the critical solution is presented might just as well apply to our problem of the affecting object.

If... appearances are not taken for more than they actually are; if they are viewed not as things in themselves, but merely as representations, connected according to empirical laws, they must themselves have grounds which are not appearances. The effects of such an intelligible cause appear, and accordingly can be determined through other appearances, but its causality is not so determined. While the effects are to be found in the series of empirical conditions, the intelligible cause, together with its causality, is outside the series. Thus the effect may be regarded as free in respect of its intelligible cause, and at the same time in respect of appearances as resulting from them according to the necessity of nature. (A 536-7/B 564-5) 
If we remember that the problem of the affecting object and of sensation gives way to two lines of explanation in the Analytic, the solution proposed above, and taken from the Dialectic, could be read as the answer Kant would have given, had he endeavoured to furnish an explicit account, within his transcendental philosophy, of the thing in itself as the "cause" of appearances. After all, it is "one and the same event", "one and the same effect" that receives a double explanation in the case of the third Antinomy; in the same manner as sensation, the result of affection, received two different causal accounts in the Analytic: an empirical, and a transcendental. Hence, there is no need to postulate as in Adickes' questionable theory of "double affection", that there are two different affections taking place.

As mentioned before, such a parallel can only be drawn cautiously, because freedom and the thing in itself refer to different problems. The conclusion of the transcendental Dialectic concerning the status of freedom as well as all transcendental ideas is that we cannot attain any knowledge of them: they remain wholly "problematic". But this conclusion is directed mainly against the pretensions of dogmatic metaphysicians, who did not hesitate to pronounce upon the existence or inexistence of a free cause in the world. For Kant, the functioning of a free cause is problematic, in the same way as an immortal soul and a necessary being endowed with all reality, remain an insoluble problem from a theoretical standpoint. In the three dialectic ideas of reason, a dogmatic statement is made about the inner nature of a transcendent object: for example, the simplicity of the soul, the reality of freedom and the necessity of a being defined as omnitudo realitatis. In this regard, the problem of the affecting object is radically different, although it must be dealt with on the same level of discourse: transcendental philosophy.

In explaining affection, and sensation -- its effect -- in terms of the thing in itself, Kant does not intend to establish any knowledge about the type of causality at work nor does he try to determine the correlate of appearance, beyond saying that it is "heterogeneous" ${ }^{29}$ and indeterminate, that is, a "mere something" (A 277/B 333) which is definitively out of reach of our knowledge. Following the principle of causality in its empirical employment which states that "everything that happens, that is, begins to be, presupposes something upon which it follows according to a rule" (A 189), Kant refuses, using the category of causality for the thing in itself, to specify the "rule" or the kind of causal action involved and to determine the essence of the acting cause. Thus, when he employs the category of causality for the thing in itself in the Critique of Pure Reason, it is clear that he does not exceed in any way the very modest claims attached to a transcendental usage. "The merely transcendental employment of the categories is, therefore, really no employment at all ['for the knowing of anything': Nachträge, CXXVII] and has no determinate object, not even one that is determinable in its mere form." (A 247-8/B 304,

${ }^{29}$ Prolegomena, § 57, AK, IV, 355. 
emphasis added)

Yet it would be a mistake to conclude that because the thing in itself, as the correlate of the appearances, remains indeterminate, its existence itself is problematic. The critical philosopher knows that there is something beyond the appearance but he/she does not know what it is. Already in the Aesthetic, it is only the nature of the thing in itself that is said to be "problematic", not its actuality (A 38/B 54). Nonetheless, there is a strong temptation to declare that the very existence of the thing in itself, together with its nature, is on the whole problematic. One is led to this conclusion when one identifies the thing in itself with the Noumenon, whose status as such is manifestly problematic. But it must be stressed that Kant envisages the status of the Noumenon as problematic only if it is taken in its "positive" meaning. According to this meaning, the Noumenon is considered the object of an intellectual intuition, the constitution of which remains totally unknown to the human being. Hence, the Noumenon is problematic as an object of intellectual intuition precisely because this mode of intuiting is altogether problematic. "...we have no intuition, indeed not even the concept of a possible intuition, through which objects outside the field of sensibility can be given..." (A 255/B 310) But this has little to do with the critical claim that we have knowledge of the existence of a mere something beyond the appearances: the thing in itself.

Another danger encountered in considering the thing in itself as a mere "logical possibility" ${ }^{30}$ is that one can be led to consider it on the same level as the ideas of pure reason. In accordance with Kant's critical solution of the dialectic use of pure reason, one might then come to confer on the thing in itself a regulative role, similar to that attributed to the transcendental ideas. For example, Eva Schaper classifies the thing in itself under the heading "heuristic fictions", which is indeed the title reserved by Kant for the problematic ideas of reason in their regulative use. ${ }^{31}$ Rescher makes a similar point when he interprets the thing in itself in relation to the Principle of Sufficient Reason as a regulative principle (as opposed to the principle of causality belonging to the understanding proper) suited to characterize the transcendental tasks that correspond to the ideas of reason. ${ }^{32}$

\footnotetext{
${ }^{30}$ Ermanno Bencivenga, "Identity, Appearances, and Things in Themselves," Dialogue 23 (1984): 430, notes 18 and 19.

${ }^{31}$ Eva Schaper, "The Kantian Thing in Itself as a Philosophical Fiction," The Philosophical Quarterly 16 (1966): 238: "Kant himself did not include the thing-in-itself among his ideas of reason, the only group of concepts which, in the first Critique, he admitted as heuristic fictions. My case for including it nevertheless is based -- as was Vaihinger's -- on the similarity in logical behaviour of this concept and those which Kant himself designated as leading to 'merely regulative principles'."

${ }^{32}$ Rescher, "Noumenal Causality," 178.
} 
I on the other hand tend to envisage the thing in itself, so long as it is said to be the cause of the appearances, as constitutive, and not regulative, with respect to the possibility of experience. If the ideas of reason, in their regulative role, are assigned to the search for the unconditioned, that is, for the complete series of the conditions of experience, then the thing in itself does not have anything to do with these transcendent tasks of pure reason but belongs to the framework of the conditions of possibility of every single experience. It is at least as "constitutive" of the experience as the transcendental subject itself. Therefore, the thing in itself pertains to arguments in the first half of the Critique (if not exclusively to a question raised in the Aesthetic) but certainly not in the Dialectic. The knowing subject discovers through the philosophical process of self-examination that, if a priori synthetic judgments are to be possible at all, that is, if there are to be universal and necessary truths, the objects of knowledge must be appearances. Yet empirical objects, although they are mere appearances, are nonetheless given to us. This means that if an appearance occurs whose manifold is not generated by the knowing subject itself, then an external cause must exist, although it be unknowable. In other words, the thing in itself is not regulative but constitutive of the very possibility of experience, and therefore, from a transcendental vantage point, its existence is not merely problematic, but assertoric. Kant's numerous statements against the charge of idealism state as much. ${ }^{33}$

In the preceding sections, I have tried to show that Jacobi's famous phrase according to which one cannot enter the Kantian system without the affecting object, but cannot stay in it on the basis of this very presupposition, is false. On the contrary, Kant is perfectly at ease with his theory of affection even though it allows two different modes of explanation. I have sought to indicate in what sense these -- apparently conflicting -- modes of explanation can be part of a coherent account of the conditions of human knowledge, more precisely, in what sense they are both required. All in all, Kant cannot be accused of negligence when he uses the pure concept of cause to depict the effect of the thing in itself on sensibility. This transcendental use of the

${ }^{33}$ See for example Prolegomena, AK IV, 289; trans. L. W. Beck, Prolegomena to any Future Metaphysics, New York, The Liberal Arts Press, 1951, 36-37: "Consequently I grant by all means that there are bodies without us, that is, things which, though quite unknown to us as to what they are in themselves, we yet know by the representations which their influence on our sensibility procures us. These representations we call 'bodies', a term signifying merely the appearance of the thing which is unknown to us, but not therefore less actual. Can this be termed idealism? It is the very contrary...The existence of the thing that appear is thereby not destroyed, as in genuine idealism, but it is only shown that we cannot possibly know it by the senses as it is in itself." See also, ibid., AK IV, 293-294; and Kritik der reinen Vernunft, B XX: "This situation yields, however, just the very experiment by which, indirectly, we are enabled to prove the truth of this first estimate of our a priori knowledge of reason, namely, that such knowledge has to do only with appearances, and must leave the thing in itself as indeed real [wirklich] per se, but as not known to us." 
category is, as we have seen, permissible. At least, I have tried to make sense of it through a reconstruction of the argument Kant would have provided, had he deemed to justify this truly exceptional use of the categories from the standpoint of his transcendental philosophy.

Now Kant did not explicitly provide this justification. Thus the concept of cause applied to the thing in itself appears out of place, especially with regard to the prohibitions of the Critique concerning the transcendental employment of the categories. In this sense, Kant can be suspected of negligence. Yet the absence of such a justification can be explained, as far as I can see, by two reasons: first, the thing in itself considered as the correlate of the appearance is related to the material conditions of experience, whereas only the formal conditions seem to come into the foreground in the Critique; secondly, in the Methodology of Pure Reason, Kant's remarks on the meta-critique of pure reason or, if we prefer, on the workings of his philosophical discourse are rather scarce and call for a reconstruction as the one briefly sketched here with the theme of self-referentiality.

The contribution of this paper is that I tried to make sense of the thing in itself, as the "transcendental ground" of appearances. Rather than simply consider the thing in itself as a "necessary" concept, as in Allison's view, my purpose was to demonstrate that for Kant the actuality of the thing in itself as the cause of appearances must be necessarily posited. The thing in itself is not just an epistemic condition that we must "think", it is a critical-metaphysical assumption that must be made and thus becomes part of philosophical knowledge: the critical philosopher knows that there is something beyond the appearances. But in this case, there is nothing dogmatic about such an assumption, since it is required by the transcendental explanation of our knowledge itself. I have tried to argue that there is a legitimate philosophical use of the category of causality which links affection to the thing in itself, as long as the constraints implied by such a concept (i.e. heterogeneity and indeterminateness of the correlate) are respected, even at this higher level of argumentation. The normative constraints of such a transcendental discourse cannot be empirical, nor can they be the product of a pure invention. The self-referentiality of philosophy, as it has been sketched here, entails that the transcendental use of a category is permissible strictly in view of the explanation of the only way in which experience is rendered possible. 